\title{
Structural Vector Autoregressive (SVAR) Analysis of Maize Prices and Extreme Weather Shocks
}

\author{
Samuel Waiguru Muriuki, Joseph Kyalo Mung'atu, Antony Gichuhi Waititu \\ Department of Statistics and Actuarial Sciences, Jomo Kenyatta University of Agriculture and Technology, Nairobi, Kenya \\ Email address: \\ waiguruanalyst@outlook.com (S.W.Muriuki),j.mungatu@fsc.jkuat.ac.ke (J. K. Mung'atu), agwaititu@gmail.com (A. G. Waititu)
}

\section{To cite this article:}

Samuel Waiguru Muriuki, Joseph Kyalo Mung'atu, Antony Gichuhi Waititu. Structural Vector Autoregressive (SVAR) Analysis of Maize Prices and Extreme Weather Shocks. International Journal of Data Science and Analysis. Vol. 4, No. 5, 2018, pp. 79-88.

doi: $10.11648 /$ j.ijdsa.20180405.12

Received: September 18, 2018; Accepted: October 16, 2018; Published: November 16, 2018

\begin{abstract}
Food prices have experienced enormous movements and volatility in the recent past which can be predominantly attributed to climate change. Extreme weather events such as drought, flooding and heat waves have adverse effects on agricultural production in areas where agriculture is weather reliant. Among the extreme weather events experienced in Kenya is a drought in 2008/09 which led to a record increase in food prices. It is against this backdrop that this study sought to investigate the dynamic relationship between maize prices and extreme agro-climatic indicators. The study uses structural vector autoregressive (SVAR) tools; Granger causality, Impulse Response Function (IRF) and Forecast Error Variance Decomposition (FEVD) to examine the dynamic relationship between extreme weather indicators (minimum and maximum temperature and precipitation) and wholesale maize prices. Using different lag length determinant criterion, reduced-form VAR (2) is highlighted as the best model to fit the study data past weather and maize prices information over a data period spanning from January 2000 and December 2016. The study established that there exists granger causality between maize prices and weather variables. Agro-climatic indicators are therefore significant in predicting future maize prices. Principally, this significance can be inferred from the reliance of local agricultural production on phenological patterns. Maize price shocks exhibited inflationary effects on future maize prices, while a shock in weather variables has depreciating effects after three months. With regard to forecast variance, $30-39 \%$ of maize price variations resulted from its own shocks. The rest is attributed to precipitation (29-39\%); maximum temperature (24-26\%); and minimum temperature (7-8\%).
\end{abstract}

Keywords: Structural Vector Autoregressive (SVAR), Granger Causality, Forecast Error Variance Decomposition (FEVD), Impulse Response Function (IRF)

\section{Introduction}

Since the turn of $21^{\text {st }}$ century, global climate change debate has gained traction with many scientific studies undertaken to understand the ramifications of this phenomenon. Generally, climate change, a phenomenon caused by anthropogenic factors and natural processes, has proven to be a challenging environmental challenge that has potential significantly impact the world economy. However, the dependence of agriculture on phonological factors has augmented the susceptibility of the sector to climatic patterns especially in the developing countries.

Precisely, climate change, as defined by FAO, is the variation in climatic patterns derived from emission of greenhouse gases (GHGs) such as carbon dioxide $\left(\mathrm{CO}_{2}\right)$, nitrous oxide $\left(\mathrm{N}_{2} \mathrm{O}\right)$ and methane $\left(\mathrm{CH}_{4}\right)$ through deforestation, combustion, industrialization and urbanization [10]. Climate change continues to pose a threat to majority of people across the globe due to its effects on agriculture, water resources, forests, snow cover and the resulting geological processes, such as desertification, flood and landslides. According to McPhail et al, climate change leads to rising sea levels, extreme rainfall and drought in areas that had hitherto experienced normal rainfall and drought, as well as unpredictability in weather conditions, thus affecting agricultural production the most [24].

In light of this significance of weather variations on agricultural production, it becomes imperative to study the 
structural relationship between maize prices (the staple crop in large parts of Africa and other developing countries) and climatic variables, as the latter has been attributed to the erratic movements of the former. In spite of remarkable technological development, crop potential and production in many countries continues to depend highly on weather patterns and climate indicators, such as precipitation, temperature, soil moisture and vapor pressure. In Kenya, maize production, both small scale and large-scale, largely relies on rainfall as the source of water since irrigation techniques are not employed.

Agriculture is a key sector in Kenya s economy, contributing to approximately $26 \%$ of the total Gross Domestic Product (GDP), and another $27 \%$ of the same, through linkages with other sectors. It is the backbone of the country's economy. In terms of employment, agriculture employs over $40 \%$ of the total population and $70 \%$ of Kenyans living in rural areas. According to statistics by FAO, the small-scale farming sub-sector, which primarily entails mixed crop and livestock farming, accounts for over $75 \%$ of the total agricultural output [10]. Maize is the staple food in Kenya and forms the largest bank of calories for majority of Kenyans. Specifically, each person is estimated to consume approximately 98 kilograms of maize per annum, translating to national maize consumption of 30 to 34 million bags annually. This makes the issue of maize price more pertinent to a majority of Kenyans.

Given the above insights, a study on specific climatic indicators (such as rainfall and temperature) on Kenya's maize production forms the starting point to understanding the effects of climatic variability on agricultural production, and subsequently on food prices. This research work utilizes a structural vector analysis approach to investigate the influence of climatic unevenness on food prices, which is extremely important in forecasting future prices with reference to current and past weather conditions.

As stated by Murungaru, weather aberrations such as extreme drought, flooding and high temperature affect all sectors of the economy with the agricultural sector suffering the most from these variations due to its high reliance on weather [27]. Effects of weather related strains vary from one region to the other and from one region of the country to the other. In 2003, as a result of reduced maize production, prices increased, both in rural and urban areas. In a similar fashion in 2008, several months of drought induced poor harvest which triggered the need to import maize to cover the deficit [18]. In 2008 and 2009, productions went down by 20 percent compared to three previous years [11].

In Kenya, food markets have been characterized by rising and highly volatile food prices. In 00s, food dynamics were particularly worrying as food prices hit the highest level ever recorded then, which was principally attributed to changing climate. FAOSTAT further indicated that during global 2008 food crisis, grains prices rose by $60 \%$ in one month [12]. Recently, food prices spikes in 2011 surpassed those of 2008 crisis. Jayne et al reckoned that the erratic nature of food prices poses a real threat to food security in Kenya, and is largely attributable to and dependent on phonological patterns [18].

Maize production in Kenya, which directly affects prices through market forces, is specifically through rain-reliant agricultural practices mostly undertaken by rural populace at subsistence level, and large scale production in areas such as Uasin Gishu, Eldoret, Trans Nzoia, Kitale and Vihiga [28]. This makes Kenya's ability to produce sufficient maize for domestic consumption vulnerable to variations in weather patterns. Crop production, especially of maize, is faced with negative effects of extreme weather shocks believed to be corollaries of changing climate. According to Ekpoh, extreme weather shocks have direct effect on agricultural productivity [8]. McPhail et al, utilized extreme climate indicators to investigate the effect of climatic volatility on poverty, and concluded that extreme weather events are significant factors in defining food price movements [24].

Similar to what is happening in other countries, Kenyan climate has undergone through a climatic metamorphosis. On average, Kimani stated that local temperature has increased by $1^{\circ} \mathrm{C}$ since 1960 , translating to a $0: 21^{\circ} \mathrm{C}$ per decade [20]. On the other hand, annual rainfall has exhibited an erratic trend where long-rains which are normally experienced in March and June has been exhibiting a decreasing trend, while the short rains experienced between October and December has exhibited an increasing trend. Additionally, extreme weather events such as flood and drought have intensified; becoming more frequent and calamitous.

High potential maize production areas are largely located in the Rift valley highlands covering the following counties: Nandi, Uasin Gishu, Trans Nzoia, Nakuru, Bomet and Kericho. In these areas, rainfall suitable for maize growing is experienced between April and August [19]. The households in these "grain basket" counties are typically food secure. Over half of national production and 60 percent of long rains output come from these counties. Other areas such as Mount Kenya region only grow maize for subsistence. Kilavi further observed that maize output in these counties principally governs domestic maize availability and local prices. Maize crop is the predominant crop in the Rift valley and Highland counties, with household's maize plantation averaging between 2-15 hectares. Maize requires between $600-900 \mathrm{~mm}$ of rainfall that is evenly distributed through-out the growing period. However, rainfall is more critical during flowering and silking stage. Lack of enough moisture during these stages can interfere with pollination, which can negatively affect production.

In a nutshell, the aim of this research is to investigate; firstly, the importance of weather variations in predicting maize price movements; secondly, how long a unit impulse of an extreme weather variable affects wholesale maize prices; and lastly, the proportion of forecast error of maize prices that is as a result of shocks in endogenous variables. The outcome of this study will provide actionable insights of the relationship between rainfall trends and price movements, which are valuable in policy simulation and developing food security programmes in developing countries. 
The other parts of the paper are divided as follows: part 2 explores the available work related to this study, part three explains the outline of VAR model and structural VAR tools. Part four presents the empirical results from the analysis, while part five provides the conclusion of the study.

\section{Literature Review}

Climatic variations exert strong impact and influence on many sectors including, but not limited to, forestry, agriculture, road maintenance, public transport, and tourism. Granted, agricultural sector is the main socio-economic sector that has received the most wrath of climate change. In many countries, climate, and the short-run weather, is the main determinant, or rather the driving force, of agricultural production.

Presently, there are numerous studies undertaken to establish the major causes of heightened price volatilities. The causes are divided depending on the stage on the market chain. Climatic conditions (weather shocks) are considered as the root cause in the supply side, whilst biofuels production is the main contributor on the demand side of the market chain. However, we acknowledge that the recent variations in product prices are as result of combination of factors. Understanding the importance of these factors is invaluable to policymakers. For instance, Subsidy Programmes implemented in 2017 were regulatory approaches and policy responses to cushion Kenyans from the maize high prices resulting from drought experienced in 2016/2017 in most parts of the country.

Using a thirteen-variable (agro-climatic predictors) multiple regression model, Ben, \& Abdoussallam examined the influence of climatic variability and future variations on millet productions in millet growing areas in Niger regions, and estimated the effects of climatic variations in millet production [3]. From the analysis, the most significant predictors were temperature variations, level of precipitation during growing seasons and number of rainy days, as well as erosion. The study, also projects $13 \%$ reduction attributed to climate change as a consequence of reduction of the amount of rainfall during the growing season which is combined with increased temperature.

Vector autoregressive analysis (VAR) model was first introduced in 1980 by Sims. As a result of high predictive efficiency and accuracy, the approach has gained traction in many fields, and more conspicuously in econometric modelling [35]. For instance, Hui employed the approach to study the level of pollution in the city of Hong Kong [16]. The level of pollution in various areas of Hong Kong were modeled using various VAR models such as general VAR, Space-Time vector autoregressive (STAR) and structural VAR. However, due to efficiency and predictive power, STAR model was used to study the level of pollution. Using the same approach, Rogers et al used STAR to study the demand of electricity in the Republic of Ethiopia in relation to consumption, population and gross domestic product (GDP) [32].
There are other studies that have utilized the structural analysis approach-structural vector autoregressive analysis model. Lutz used the SVAR to extricate market shocks (both demand and supply side) of commodity prices [22]. More precisely, Lutz further disentangled the crude oils real prices into; supply shocks, global demand for various commodities and demand of crude oils. Due to information asymmetry, he then employed zero instantaneous response of supply and demand of crude oil [22]. The same approach has been employed to examine movements in crude oil prices, by various scholars such as, [39]; and [24].

The application of SVAR has become progressively more popular in the recent times. Lutz used the same techniques as McPhail to examine the influence of global speculation, demand and energy shocks on maize price volatility [22]. The conclusion was that energy shocks were the main drivers of long-term maize prices volatility. Chen et al extended the work by including market movements of gasoline, corn and ethanol in the SVAR model with the structural analysis obtained through Cholesky decomposition [5]. They concluded that biofuel production has short-term effect on corn prices. Lutz used the SVAR to extricate market shocks (both demand and supply side) of commodity prices [22]. To identify the model, they used normalization, recursion and identified the model through heteroskedicity. They concluded that there were no co-movements between cotton prices and other non-agricultural commodities.

Similarly, Carter et al used SVAR model to investigate the influence of United States ethanol prices on corn prices using four structural factors: VAR system; inventory supply, inventory demand, global economic activities and supply storage stock [4]. They established that ethanol production had considerably significant effects on global maize prices, without which the prices would have been $40 \%$ less in 2012 . Conversely, Baumeister found no substantive evidence to establish the influence of oil prices on retail product prices using two-variable VAR model [2].

According to Dinku et al, monitoring and forecasting agricultural production in Kenya can provide insightful information about food security and policies and the approach that ought to be implemented to improve agricultural productivity [7]. Zhang et al employed structural vector autoregressive analysis to analyze the climatic effects on agricultural production, and consequently food prices [39]. Tewari et al evaluated the Granger-causality between climatic indicators and soybean price variations during the data period stretching from 1975-2013 in US-West Tennessee County [37].

Expanding the application of SVAR in previous studies, this research work has expanded the literature by examining the influence of extreme weather shocks and contribution of each shock on maize price variations over the period of January 2000 and June 2017. This study extends the present literature in several ways. First, unlike Tewari et al who studied the bivariate Granger causality of soybeans price and minimum/maximum temperature, this analysis involves monthly minimum/maximum temperature and rainfall which 
is highlighted as the root cause of food price variations [37]. Second, this research work conducts a full structural vector autoregressive analysis. Modeling the causal relationship among the monthly weather shocks and maize prices may reveal important information regarding their contemporaneous relationship, using VAR system. The impulse response function and variance decomposition from the SVAR model can highlight the extent to which the weather shocks influence domestic maize price movements.

\section{Research Methodology}

The objective of this paper is to estimate and trace the historical effects of extreme weather aberrations on maize price movements. The analysis will involve monthly data of maize prices in Nairobi, Nakuru, Mombasa and Eldoret over a period from January 2010 to December 2016. The climatic data applied is monthly minimum and maximum Temperature (in centigrade) and rainfall from maize growing counties, Trans Nzoia, Uasin Gichu and Embu covering the same time period. We use the structural vector autoregressive (SVAR) tools to show how extreme climatic shocks affect the maize prices at national scale.

\subsection{Construction of Rainfall Deviations and Shocks}

To construct the monthly weather shocks, we reference monthly minimum and maximum temperature and rainfall in three counties: Trans Nzoia, Uasin Gichu, and Embu counties that substantially contribute to maize production in Kenya. To suppress seasonality effects we consider monthly deviations from the long-term climatic monthly averages derived from thirty years' historical information of respective counties. Similar to studies by Lutz; Maccini \& Young and Rocha \& Soares among others, weather deviations are constructed by subtracting the natural logarithm of the longterm or historical average from the current monthly weather observations. The resulting measures are weather changes essentially indicating the percentage deviation from longterm averages, and they are measured using log-point deviations [23].

\subsection{Structural Vector Autoregressive (SVAR) Framework}

In addition to description and forecast, VAR models are also applied in structural analysis. Restrictions and assumptions are imposed on the system about casual structure under analysis, and hence the impact of an unexpected standard deviation of shocks of a specific variables on itself and other variables in the system are summarized. Causal relationships are analyzed and presented using impulse response functions (IRFs) and forecast error variance [38]. Specifically, this paper involves determining Granger causality tests, the calculation of impose response functions (IRFs) and tracing the proportion forecast error that is attributable to each variable in the model.

We assume that maize prices variations in Kenya are adequately represented by the structural equation below. A generalized vector autoregressive model of $Y_{t}$ given by

$$
Y_{t}=A_{0}+A_{1} Y_{t}+\mu_{i}
$$

where $A_{0}$ is a $k$ constant vector, $Y_{t}$ is a $k$ vector of realizations of endogenous variables and $A_{0}$ is an interrelation matrix among the endogenous variables where $\mathrm{i}>0$ and $\mathrm{m}_{\mathrm{t}}$ is a vector of independent and identically distributed (i.i.d) random vectors (white noise) with mean zero and with a positive definite covariance matrix. Fackler and Sims proposed a structural vector autoregressive model using econometric analysis as it is imperative to examine the dynamic relationship between endogenous variables. In general, SVAR system can be represented as a function of backshift operator (L) as follows:

$$
Y_{t}=D(L) Y_{t}+e_{t}
$$

Where $D(L)=A_{0}^{-1} A_{1}(L)$ and $e_{t}$ represent the residuals of reduced VAR model. Generally, the SVAR model has many parameters which make interpretation difficult due to complex interactions between the endogenous and exogenous variables. Owing to these assertions, the dynamic nature of reduced-form VAR system is usually summarized using the structural-analysis tools: Granger Causality, Impulse Response Function (IRF) and Forecast Error Variance Decomposition (FEVD).

\subsection{Determination of Lag Length}

We follow Lutkepohl's interactive procedure that involves the following steps: specification, model estimation, and diagnostic checking [21]. For this study, model specification involves selecting the optimal VAR order, p. Granted, determination of lag length is an important preliminary step in model building and structural analysis. In this study, we employ the commonly used information criteria to choose the optimal lag order. These include Akaike In-formation Criterion (AIC) proposed by Akaike , Hannan-Quinn (HQ) proposed by Hannan, \& Quinn, and Bayesian information criterion (BIC) suggested by Schwarz . Under the normality assumption the following criteria are used:

$$
\begin{gathered}
\operatorname{AIC}(\mathrm{h})=\ln \left|\sum_{\mathrm{h}, \varepsilon}^{-}\right|+\frac{2}{\mathrm{~T}} \mathrm{hk}^{2} \\
\mathrm{BIC}(\mathrm{h})=\ln \left|\sum_{\mathrm{h}, \varepsilon}^{-}\right|+\frac{\ln (\mathrm{T})}{\mathrm{T}} \mathrm{hk}^{2} \\
\mathrm{HQ}(\mathrm{h})=\ln \left|\sum_{\mathrm{h}, \varepsilon}^{-}\right|+\frac{\ln (\ln (\mathrm{T}))}{\mathrm{T}} \mathrm{hk}^{2}
\end{gathered}
$$

where $\mathrm{T}$ is the number of observation and $\mathrm{p}$ is the optimal lag length and $\widehat{\sum_{h, \varepsilon}}$ is the maximum

Likelihood estimate (MLE) of $\sum_{\mathrm{h}, \varepsilon}$. Nevertheless, consistency of information criteria in determining the lag length has a limitation in that it requires the existence of a true model, which unfortunately does not exist in reality [38]. 
To this effect, Shibata constructed the asymptotic optimality properties of AIC [34]. Apart from the above criteria, Brandt and Bessler proposed an alternative method to determine the number of autoregressive lags in multivariate time series. The statistics is expressed as follows:

$$
\mathrm{m}(\mathrm{k})=-\left(\frac{\mathrm{T}-1}{2-\mathrm{hk}}\right)\left(\left(\ln \sum_{\mathrm{h}, \varepsilon_{1}}^{-}\right)-\left(\ln \sum_{\mathrm{h}, \varepsilon_{2}}^{-}\right)\right)
$$

where $\mathrm{h}$ is the autoregressive optimal lag order and $\mathrm{k}$ is the number of endogenous variables. The statistics is effective in determining lag length in multivariate time series. It is asymptotically $\chi_{\mathrm{k}^{2}}^{2}$ distributed $\left(\mathrm{k}^{2}\right.$ degrees of freedom). After determining the optimal lag length, VAR system is reestimated and the insignificant lags are disregarded from the model.

\subsection{Model Checking}

There is a gallery of procedures available for checking the adequacy of VAR models. However, they should be employed cautiously to ensure consistency of inferences. Some of the methods use estimated residuals to test whether they conform to white noise assumption. Others, use nonnormality, autocorrelation and conditional heteroscedasticity tests [21]. However, for this study, analysis residual autocorrelation will be used to test the adequacy of VAR system using the multivariate Portmanteau test. The procedure tests the null hypothesis that all the crosscorrelations matrix of selected VAR model innovations is not different from zero. $\mathrm{H}_{0}=\mathrm{E}\left(\mathrm{e}_{\mathrm{t}} \mathrm{e}_{\mathrm{t}-\mathrm{i}}^{\prime}\right)=0$ where $\mathrm{i}=$ $1,2,3 \ldots$ against the alternative hypothesis that at least one auto covariance, hence autocorrelation, is not equal to zero.

To increase the efficiency of the statistics, Hosking modified Portmanteau test, to match the estimated and actual distribution. The proposed statistic is as follows:

$$
\mathrm{Q}(\mathrm{p})=\mathrm{T}^{2} \sum_{\mathrm{j}-1}^{\mathrm{h}} \frac{1}{\mathrm{~T}-\mathrm{j}} \operatorname{tr}\left(\sum_{\mathrm{j}}^{-} \sum_{0}^{\prime} \sum_{\mathrm{j}}^{-1} \sum_{\mathrm{j}}^{-}\right)
$$

The choice of $h$ is important and it should be larger than $p$ to get a considerably good approximation. However, using a too large $\mathrm{h}$ will reduce the power of the test.

\subsection{Stationarity and Stability Test}

Determination of the stationarity of individual time series is important as it ascertains the order of integration, and in presence of non-stationarity, the series are differenced to make them stationary. The method of classifying nonexplosive processes is that, processes that are stationary are denoted by $\mathrm{I}(0)$, while process that become stationary after first, and second differences are denoted by I(1) and I(2) respectively. Augmented, Dickey-Fuller (ADF) statistic is used to ascertain whether the process is stationary.

A k-dimensional VAR system $Y_{t}$ is said to be weakly stationary if; firstly, the expectation of the random vector $Y_{t}$ is a vector of constants, and secondly $\operatorname{cov}(\mathrm{Y})=\mathrm{E}(\mathrm{Y}-$
$\mu)(\mathrm{Y}-\mu)^{\prime}=\sum_{\mathrm{y}}$ is a $\mathrm{k} \times \mathrm{k}$ positive definite matrix. Hence, $Y_{t}$ is said to be weakly stationary if the expectation and covariance are time invariant, in other words, the first two moments do not depend on time. Implicitly, this requires the first two moments of the random vector to exist.

A reduced VAR model is said to be stable provided if the Eigen values of $A_{1}$ are less than unit in absolute terms. The Eigen values must satisfy the following equation

$$
\operatorname{det}\left(\mathrm{I}_{2} \lambda-\mathrm{A}_{1}\right)=0
$$

and equal to the inverse of roots to characteristic equation,

$$
\operatorname{det}\left(I_{2}-A_{1} z\right)=0
$$

Hence, the reduce form of VAR is stationary, a stable system is stationary while the reverse is not true, provided the roots of the equation lies outside a complex unit circle.

\subsection{Structural Analysis Tools}

The typical VAR (h) model is characterized by many parameters, making it difficult to make interpretations due to complexity resulting from interactions and dependence between the structural variables in the system. To circumvent this, the dynamic properties of VAR (h) are often summarized using structural tools of analysis namely; (i) Granger causality tests, (ii) impulse response functions (IRFs) and (iii) forecast error variance decompositions (FEVD). Below is a brief description of the above structural analysis methods:

\subsubsection{Granger Causality}

Granger proposed the principle of granger causality to describe the significance of macroeconomic variables in predicting other variables [13]. Previously, the concept of causality was understood as the asymmetrical relationship between variables. In a bivariate model of variables $\mathrm{X}$ and $\mathrm{Y}$, Tsay postulates that $\mathrm{Y}$ causes $\mathrm{X}$ if bivariate prediction is more accurate compared with univariate, where accuracy is measured using forecast error [38]. Using forecast variance Granger defined causality [13] as;

$$
\delta^{2}(\mathrm{X} \mid \mathrm{V})<\delta^{2}(\mathrm{X} \mid \mathrm{V}-\mathrm{Y})
$$

This means that the forecast variance of $X$ given all the available information $\mathrm{V}$, is less than the variance when $\mathrm{X}$ with information less the information embedded in variable $\mathrm{Y}$. In this case $\mathrm{Y}$ is said to Granger cause $\mathrm{X}$. That notwithstanding, the application of the test is subjective in the sense that the research decides the relevance of the information.

\subsubsection{Impulse Response Function (IRF)}

The impulse response function is used to analyze the dynamic effects of the VAR system when the model receives as shock. The dynamic response of market prices (wholesale maize prices) to the changes in weather indicators can be examined through impulse response analysis. It uses moving average (MA) representation of the VAR model to trace the 
dynamic effects of shocks to the system on each variable under investigation [36]. Here, our interest is the dynamic response of wholesale market prices to the shocks of monthly maximum and minimum temperature and precipitation.

Consider Moving average representation of the reducedform VAR ( $p$ ) system at time $t+s$.

$$
\left[\begin{array}{l}
\mathrm{y}_{1(\mathrm{t}+\mathrm{s})} \\
\mathrm{y}_{2(\mathrm{t}+\mathrm{s})}
\end{array}\right]=\left[\begin{array}{l}
\mu_{1} \\
\mu_{2}
\end{array}\right]+\left[\begin{array}{ll}
\theta^{0}{ }_{11} & \theta^{0}{ }_{12} \\
\theta^{0}{ }_{21} & \theta^{0}{ }_{22}
\end{array}\right]\left[\begin{array}{l}
\varepsilon_{1 \mathrm{t}} \\
\varepsilon_{2 \mathrm{t}}
\end{array}\right]+\cdots+\left[\begin{array}{ll}
\theta^{\mathrm{s}}{ }_{11} & \theta^{\mathrm{s}}{ }_{12} \\
\theta^{\mathrm{s}}{ }_{21} & \theta^{\mathrm{s}}{ }_{22}
\end{array}\right]\left[\begin{array}{l}
\varepsilon_{1(\mathrm{t}+\mathrm{s})} \\
\varepsilon_{2(\mathrm{t}+\mathrm{s})}
\end{array}\right]
$$

Therefore, a generalized structural temporal multiplier is:

$$
\theta^{\mathrm{s}}{ }_{\mathrm{ij}}=\frac{\partial \mathrm{y}_{\mathrm{i}(\mathrm{t}+\mathrm{s})}}{\varepsilon_{\mathrm{jt}}}
$$

The structural impulse response functions (IRFs) is a plot of $\theta^{s}{ }_{i j}$ against $s$, where; $j=1,2$. Typically, the plots is the summary of how impulse of the structural shocks at time $t$ impacts the level of $Y_{t}$ at time $t+s$ for different value of $s$.

\subsubsection{Forecast Error Variance Decomposition (FEVD)}

The other practical question addressed by structural VAR model is how much of the forecast error variance (FEV) or mean squared prediction error (MSPE) of $\mathrm{Y}_{\mathrm{t}+\mathrm{s}}$ on time horizon $\mathrm{s}=1,2,3,4,5,6 \ldots$ is accounted for by each structural shock. In a stationary time series model, the limit of FEVD, as $s \rightarrow \infty$ is the variance decomposition of $Y_{t}$ because the forecast error covariance matrix or MSPE converges to unconditional covariance matrix of $Y_{t}$. Thus, for stationary systems, one may construct MSPE decomposition for horizon infinity [17].

In other words, FEVD is applied to trace the proportion or percentage of variations of innovations in forecasting of $Y_{1}$

$$
\operatorname{var}\left(\mathrm{y}_{\mathrm{it}}-\hat{\mathrm{y}}_{\mathrm{it}+\mathrm{s} \mid \mathrm{t}}\right)=\delta_{\mathrm{i}}{ }^{2}(\mathrm{~s})=\sum_{\mathrm{i}=1}^{2} \delta_{\mathrm{i}}{ }^{2}\left(\left(\theta_{\mathrm{ij}}{ }^{(0)}\right)^{2}+\cdots+\left(\theta_{\mathrm{ij}}{ }^{(\mathrm{s}-1)}\right)^{2}\right)
$$

Therefore the fraction of forecast error from $y_{i(t+s)}$ attributable to $\varepsilon_{i}$ (where $i, j=1,2$ in case of bivariate VAR)

$$
\rho_{\mathrm{ij}}(\mathrm{s})=\frac{\delta_{\mathrm{i}}{ }^{2}\left(\left(\theta_{\mathrm{ij}}{ }^{(0)}\right)^{2}+\cdots+\left(\theta_{\mathrm{ij}}{ }^{(\mathrm{s}-1)}\right)^{2}\right)}{\sum_{\mathrm{i}=1}^{2} \delta_{\mathrm{i}}{ }^{2}\left(\left(\theta_{\mathrm{ij}}{ }^{(0)}\right)^{2}+\cdots+\left(\theta_{\mathrm{ij}}{ }^{(\mathrm{s}-1)}\right)^{2}\right)}
$$

\section{Empirical Results}

This chapter presents the findings of this work. The findings are presented and outlined with reference to the objectives of the study, as stated in the previous chapters. The specific aims were to model the variables using vector autoregressive model, and employ the structural tools to determine the dynamic relationship between the endogenous variables. Analysis was carried out in R software environment using "vars", "MTS", and "MSBVAR" packages.

\subsection{Description of the Data}

The information of maximum and minimum temperature for individual weather station in Uasin Gichu, Trans Nzoia and Embu were obtained from the Department of Meteorological, in the Ministry of Environment and Natural Resources. In addition, monthly average of the selected and $Y_{2}$ at the time $t+s$ based on the available information at time $t$ that is as a result of variability in the structural shock of $e_{1}$ and $e_{2}$ along the forecast horizon [6]. This decomposition is achieved through Wold representation for $\mathrm{Y}_{\mathrm{t}+\mathrm{s}}$, as follows: This may be interpreted that not a single structural shock affects $Y_{t}$ in the long-run.

$\mathrm{y}_{\mathrm{t}+\mathrm{s}}=\mu+\mu_{\mathrm{t}+\mathrm{s}}+\Psi_{1} \mu_{\mathrm{t}+\mathrm{s}-1}+\cdots+\Psi_{\mathrm{s}-1} \mu_{\mathrm{t}+1}+\Psi_{\mathrm{s}} \mu_{\mathrm{t}}+\Psi_{\mathrm{s}-1} \mu_{\mathrm{t}-1}$

The most accurate linear forecast of $Y_{t+s}$ based on the available information at time $t$ is

$$
\hat{y}_{t+s \mid t}=\mu+\Psi_{s} \mu_{t}+\Psi_{s+1} \mu_{t-1}
$$

Hence, the forecast error is given by:

$$
y_{i t}-\hat{y}_{t+s \mid t}=\sum_{j=1}^{2} \theta_{i j}^{0} \varepsilon_{i t+s}+\cdots+\theta_{i j}^{s-1} \varepsilon_{i t+1}
$$

The forecast error variance of $i$ can therefore be written as a function of structural shocks:

weather stations was calculated to represent the local climatic condition in maize growing areas. Monthly data of historical maize prices (Whole prices) were obtained from the Ministry of Agriculture, Livestock and Fisheries. We applied Kenya s consumer price index (CPI) (January 2000), retrieved from Kenya National Bureau of Statistics (KNBS), to adjust the price for inflation.

\subsection{Descriptive Statistics}

With regard to maize prices, Nairobi had the highest mean price per bag of Kshs. 2,046.01 and maxi-mum price nationally of Kshs. 4,225.00, which was equal to the highest price registered in Eldoret. Contrary, the smallest mean price was registered in Eldoret, Kshs. 1,803.42. However, as indicated in Table 1 below, the monthly prices in Kenya exhibited high dispersion indicated by high standard deviations and range. Uasin Gichu County was the coolest while Embu County was the hottest, with reference to both minimum and maximum temperature. Trans Nzoia followed by Embu registered the highest average level of precipitation, 110.45 and 99.20 millimeters respectively. In addition, Embu experienced the highest maximum rainfall during the study period. 
Table 1. Descriptive Statistics of Maize prices and Weather Indicators.

\begin{tabular}{|c|c|c|c|c|c|}
\hline Variable & Location & Mean & Standard Deviation & Minimum & Maximum \\
\hline \multirow[t]{3}{*}{ Maize Prices } & Nairobi & 2046.01 & 803.16 & 677.00 & 4225.00 \\
\hline & Eldoret & 1803.42 & 800.47 & 480.00 & 4225.00 \\
\hline & Momabasa & 1949.86 & 784.93 & 729.00 & 4030.00 \\
\hline \multirow[t]{3}{*}{ Min Temperature } & Uasin Gichu & 11.07 & 1.13 & 7.30 & 13.90 \\
\hline & Trans Nzoia & 12.48 & 1.04 & 9.50 & 18.70 \\
\hline & Embu & 14.37 & 1.05 & 12.10 & 16.50 \\
\hline \multirow{2}{*}{ Max Temperature } & Trans Nzoia & 26.25 & 1.97 & 12.50 & 33.10 \\
\hline & Embu & 23.15 & 4.47 & 12.50 & 29.10 \\
\hline \multirow[t]{3}{*}{ Rainfall } & Uasin Gichu & 92.18 & 70.44 & 0.00 & 327.70 \\
\hline & Trans Nzoia & 110.45 & 72.85 & 0.00 & 301.50 \\
\hline & Embu & 99.20 & 114.51 & 0.00 & 744.20 \\
\hline
\end{tabular}

Note: Prices (KShs per 90 Kgs Bag), Temperature (in centigrade), and Rainfall (in mm)

\subsection{Stationarity and Stability Test}

Prior to structural analysis, the stationarity of the variables under investigation was determined to avoid inconsistent estimates and spurious regression which is a common problem in time series analysis. Augmented Dickey-Fuller (ADF) test was used to determine the stationarity of time series, presented as shown in Table 2 below. All the variables, at least from empirical results, are stationary in their level form. The VAR system is stable considering that all Eigen values of the companion matrix are less than unit: $0.8957,0.6523,0.6523,0.3781,0.3781$, $0.1800,0.1800$ and 0.0616 . Hence, the system is invertible providing an infinite-moving average (MA) representation for viable impulse response function and forecast variable decomposition interpretations.

Table 2. Augmented Dickey-Fuller (ADF) Test for Stationarity.

\begin{tabular}{llll}
\hline Variables & $\begin{array}{l}\text { Integration } \\
\text { of order }\end{array}$ & $\begin{array}{l}\text { Dickey-Fuller } \\
\text { Values }\end{array}$ & P-values \\
\hline Maize Prices & $\mathrm{I}(0)$ & -3.4156 & 0.013 \\
Minimum Temperature & $\mathrm{I}(0)$ & -6.2741 & 0.010 \\
Maximum Temperature & $\mathrm{I}(0)$ & -5.3208 & 0.010 \\
Rainfall & $\mathrm{I}(0)$ & -7.5487 & 0.010 \\
\hline
\end{tabular}

Note: I $(0)=$ Integrated of order zero.

\subsection{VAR Order Selection and Estimation Results}

Given the sensitivity of the structural analysis to lag length, several information criteria, namely; BIC, AIC, HQ, $\mathrm{M}(\mathrm{p})$ were used to determine the optimal lag length of fourvariable VAR. Apart from AIC, other selection criteria suggested second-order VAR (Results in Table 3). The results are in line with what Akaike [1] postulated; Akaike information Criterion (AIC) and Bayesian criterion tend to underestimate the lag length in some situations. To affirm the selection, Multivariate Ljung-Box (Multivariate Portmanteau statistic) confirmed the adequacy of the model since the residuals of the second-order VAR are white noise, they behave well in all cases. In other words, VAR (2) successfully removes dynamic dependence among the structural variables.
Table 3. Order Selection Statistics for Vector Autoregressive (VAR) Model.

\begin{tabular}{llllll}
\hline $\mathbf{p}$ & $\mathbf{B I C}$ & $\mathbf{A I C}$ & $\mathbf{H Q}$ & $\mathbf{M}(\mathbf{p})$ & P-values \\
\hline 1 & -4.6606 & -4.6606 & -4.6606 & 0.0000 & 0.0000 \\
2 & -6.9200 & -7.1803 & -7.0750 & 496.4919 & 0.0000 \\
3 & -6.6870 & -7.2075 & -6.9969 & 17.4077 & 0.3065 \\
4 & -6.3672 & -7.1480 & -6.8322 & 17.2810 & 0.3676 \\
5 & -6.0660 & -7.1070 & -6.6859 & 20.1037 & 0.2156 \\
6 & -5.6954 & -6.9966 & -6.4703 & 7.8843 & 0.9522 \\
7 & -5.3935 & -6.9549 & -6.3233 & 19.0613 & 0.2655 \\
8 & -5.0638 & -6.8855 & -6.1486 & 14.1224 & 0.5896 \\
9 & -4.8437 & -6.9257 & -6.0835 & 31.0308 & 0.0133 \\
10 & -4.6337 & -6.9759 & -6.0285 & 31.7895 & 0.0106 \\
11 & -4.2899 & -6.8923 & -5.8396 & 10.9502 & 0.8126 \\
12 & -3.9957 & -6.8584 & -5.7003 & 17.8831 & 0.3308 \\
\hline
\end{tabular}

Residual analysis or diagnostic check is of great importance in model building. However, the adequacy of the model is determined depending upon the objective of the study. For this analysis, we considered whether the model removed serial cross-correlation in VAR (2) residuals. To affirm the selection, Multivariate Ljung-Box (Multivariate Portmanteau statistic) was applied to confirm the adequacy of the model, the residuals of the second-order VAR were white noise (See Table 4).

Table 4. Multivariate Ljung Box Test Statistics of VAR (2) Adequacy.

\begin{tabular}{llll}
\hline $\mathbf{p}$ & $\mathbf{Q}(\mathbf{h})$ & $\mathbf{d . f}$ & p-values \\
\hline 1 & 1.64 & 16 & 1.00 \\
2 & 10.63 & 32 & 1.00 \\
3 & 23.17 & 48 & 0.99 \\
4 & 35.62 & 64 & 0.99 \\
5 & 51.69 & 80 & 0.98 \\
6 & 67.04 & 96 & 0.97 \\
7 & 102.88 & 112 & 0.72 \\
8 & 124.24 & 128 & 0.58 \\
9 & 136.50 & 144 & 0.66 \\
10 & 153.42 & 160 & 0.63 \\
11 & 169.39 & 176 & 0.63 \\
12 & 189.00 & 192 & 0.55 \\
\hline
\end{tabular}

\subsection{Granger Causality}

It is worth stating that estimation of pairwise Granger causality is exceedingly sensitive to lag length. This informed implementation of several information criteria to 
determine the order of unrestricted VAR model. The optimal length of order two, VAR (2), resulted to the stated granger causality relations as presented in Table 5. All the FStatistics, where the null hypothesis is weather variable fails to granger cause prices, are statistically significant at $5 \%$ probability level. The results evince that there is a causality between wholesale maize prices and all the weather variables over the period of study. Technically, maize prices are better predicted when the selected weather variables are factored.

Table 5. Results of Granger Causality Test for Weather Variables.

\begin{tabular}{lll}
\hline Null Hypothesis & F-Statistics & P-Values \\
\hline Rainfall Shocks $/ \rightarrow$ Prices & 6.2782 & $2: 2740 \times 10^{3}$ \\
Min Temp Shocks $/ \rightarrow$ Prices & 4.7744 & $9: 4451 \times 10^{3}$ \\
Max Temp shocks $\rightarrow$ Prices & 3.5201 & $3: 1471 \times 10^{2}$ \\
\hline
\end{tabular}

$\mathrm{H} 0 ; \mathrm{A} / \rightarrow \mathrm{B}$, where $/ \rightarrow$ means "A fails to Granger cause B."

\subsection{Structural Impulse Response Functions (IRF)}

Typically, the response is presented graphically as illustrated in Figure 1 and tracks the impact of a change by one standard deviation of endogenous variable innovations on current and future values of itself and other endogenous variables through a dynamic structure of VAR system. Figure

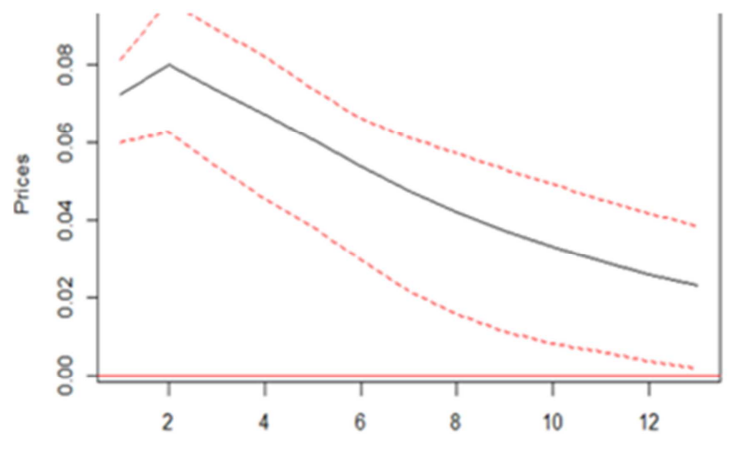

Orthogonal Impulse Response from Max Temp shocks

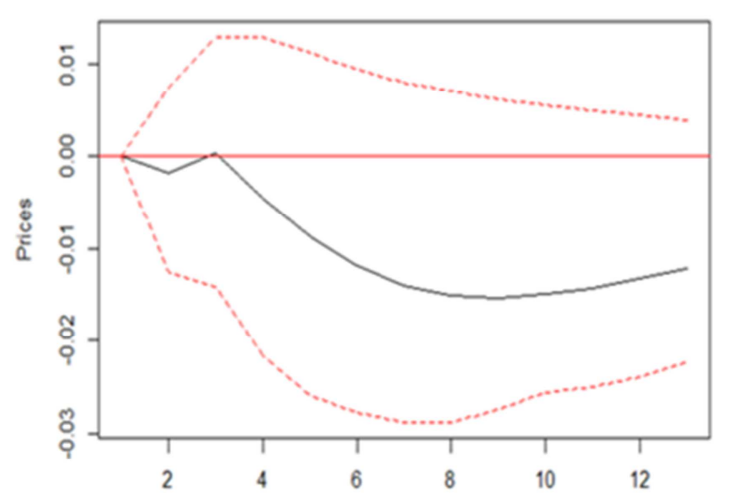

$95 \%$ Bootstrap Cl, 100 runs
1 is an IRF of 12 months' period future values. The graphs depict the following: (1) tracks maize price response to its own instantaneous one standard deviation increase (shown on Top right panel). It has positive effects that are persistent and remain positive throughout the years. This implies that prices shocks have inflationary effects on prices with the highest recorded after two months. (2) The response of maize prices to minimum temperature shocks (shown in Top Left Panel) is positive during the first three months and then decreases into negative effect to the fifth month and then starts to increase. This suggests that an increase in minimum temperature leads to an in increase in maize prices for the first three months and then effects stabilize after five months. (3) The response of maize prices to maximum temperatures (shown in bottom left panel) declines immediately and builds up after the second month and there after decreases continuously. This indicates that maximum temperature has a negative effect on maize prices during the data period. (4) Conspicuously, the rainfall shock (shown in the bottom right panel) has a positive effect which increases for the first two months with the highest recorded during the second month and then erratically reduces to negative effects and level off after the fourth month.
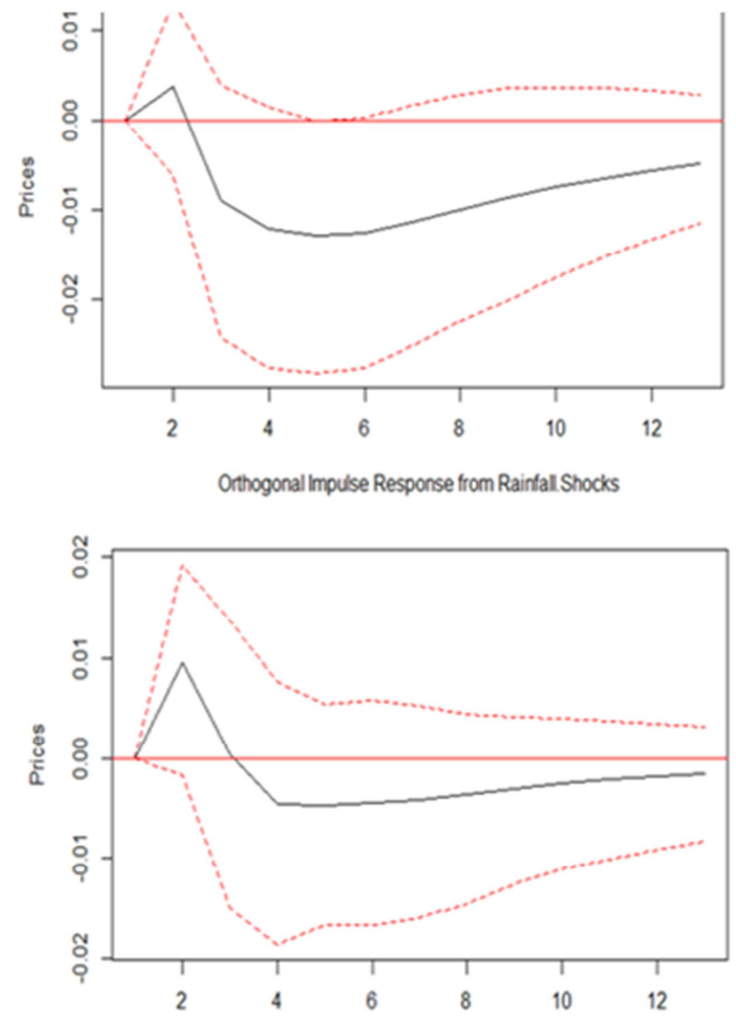

$95 \%$ Bootstrap C, 100 runs

Figure 1. Impulse Response Function of Prices on Weather Variables.

\subsection{Variance Decomposition of Forecast Errors}

Illustratively, a shock in a specific variable will definitely affect itself and transmit to other variables in the VAR system through a dynamic structure.
As illustrated in Table 6, during the first month, 32.1\% and $53.1 \%$ of the changes in wholesale maize price emanated from maize price itself and maximum temperature variables respectively, while the rest is largely explained by minimum temperature (13\%). In the second month, $40.3 \%, 28.9 \%$ and 
$21.5 \%$ of the changes in maize prices are attributed to changes in the level of precipitation, maximum temperature and maize price shocks respectively. During the third month, much of the changes in maize prices is explained by rainfall, accounting to $38.7 \%$. In the same month, the change of maize prices that resulted from maize prices shock itself, maximum temperature and minimum temperature was $26.0 \%, 28.0 \%$ and $7.4 \%$ respectively. Henceforth, the proportion of forecast variance attributable to each endogenous variable remained fairly stable: maize prices between $30-39 \%$, minimum temperature between $7-8 \%$, maximum temperature between 24- $26 \%$ and rainfall between $29-35 \%$. This shows that maize price dynamics them-selves, maximum temperature and rainfall variations are the principal determinants of maize price movements in Kenya.

Table 6. Forecast Variance Error Decomposition of Maize Price in Kenya.

\begin{tabular}{|c|c|c|c|c|c|}
\hline Months & Std. Error & Maize Prices & Min Temp. Shocks & Max Temp. Shocks & Rainfall Shocks \\
\hline 1 & 0.1235 & 32.0725 & 13.8233 & 53.1300 & 0.9743 \\
\hline 2 & 0.2199 & 21.4785 & 9.3427 & 28.8679 & 40.3109 \\
\hline 3 & 0.2465 & 25.9454 & 7.4350 & 27.9464 & 38.6732 \\
\hline 4 & 0.2566 & 30.7473 & 7.1050 & 26.2858 & 35.8620 \\
\hline 5 & 0.2658 & 33.7810 & 7.4933 & 25.0247 & 33.7010 \\
\hline 6 & 0.2724 & 35.8390 & 7.5016 & 24.3692 & 32.2902 \\
\hline 7 & 0.2778 & 36.9696 & 7.4801 & 24.1975 & 31.3528 \\
\hline 9 & 0.2854 & 37.8258 & 7.29009 & 24.7369 & 30.1473 \\
\hline 10 & 0.2875 & 38.0507 & 7.18299 & 24.9494 & 29.8170 \\
\hline 11 & 0.2890 & 38.2039 & 7.13709 & 25.0905 & 29.5686 \\
\hline 12 & 0.2900 & 38.3059 & 7.1597 & 25.1597 & 29.3747 \\
\hline
\end{tabular}

\section{Conclusion}

The statistical analysis exhibited essential empirical evidences of co-movements between maize prices and weather indicators in Kenya. With regard to summary statistics, Nairobi and Eldoret indicated the highest and lowest maize prices respectively. Trans Nzoia recorded the highest amount of rainfall and level of temperature. The data is fitted to a reduced-form VAR (2), which efficaciously removed dependence among the systems residuals, the adequacy of the model was paramount in carrying out structural analysis. From the analysis, weather variation, and more so the rainfall, is important in predicting future maize prices. The importance of weather information in predicting maize prices is in agreement with the available literature. The result of impulse response function shows the representation of a response of a process in autoregressive system to a one standard deviation of its innovations and that of other processes in the system. With regard to forecast error decomposition, during the first month, price fluctuations are largely attributed to price itself and maximum temperature, and variations in the second month is largely inferable from the level of precipitation. After the third month, the proportion attributable to each variable stabilizes and are approximately ranked (significance in predicting maize prices) as follows: prices, precipitation, maximum temperature, and minimum temperature.

\section{References}

[1] Akaike. (1976). Canonical Correlation Analysis of Time Series and the Use of an Information Criterion. Systems Identification: Advances and Case Studies. Academic Press, New York.
[2] Baumeister, Christiane, \& Kilian, L. (2013). Do Oil Price Increases Cause Higher Food Prices? No. 2013/10. CFS Working Paper.

[3] Ben, \& Abdoussallam. (2002). Impact of Climate Change on Agricultural Production in the Sahel Part 1. Methodological Approach and Case Study for Millet in Niger. Climatic Change.

[4] Carter, Colin, Rausser, G., \& Smith. A. (2013). The effect of the US Ethanol Mandate on Corn Prices. Department of Agricultural and Resource Economics, University of California, Davis.

[5] Chen, Q., Colson, Escalante, \& Wetzstein. (2012). Considering Macroeconomic Indicators in the Food before Fuel Nexus. Energy Economics.

[6] Chuku, Effiong, \& Sam. (2010). Oil Price Distortions and their Shorthand Long-Run Impacts on the Nigerian Economy. MPRA Paper No. 24434.

[7] Dinku, Ceccato, Grover-Kopec, Lemma, \& Conner. (2007). Validation of Satellite Rainfall Products over East Africa's Complex Topography. International Journal of Remote Sensing.

[8] Ekpoh, I. (2010). Adaption to The Impact of Climatic Variations on Agriculture by Rural Farmers in North-western Nigeria. J Sustain Dev.

[9] Fackler. (1988). Vector Autoregressive Techniques for Structural Analysis. Rev. Anal. Econ.

[10] FAO. (2013). Rural Youth Employment in Developing Countries: A Global View. Rural Employment Overview/Synthesis No. 1.

[11] FAOSTAT. (2013). Food and Agriculture Organization of the United Nations.

[12] FAOSTAT, D. (2013). Food and Agriculture Organization of the United Nations. Statistical Database. 
[13] Granger. (1969). Investigating Causal Relations by Econometric Models and Cross-Spectral Methods. Econometrica.

[14] Hannan, \& Quinn. (1979). The Determination of the Order of an Auto-regression. Journal of the Royal Statistical Society, Series B 41 .

[15] Hosking. (1980). The Multivariate Portmanteau Statistic. Journal of the American Statistical Association.

[16] Hui. (2004). Application of Vector Autoregressive Models to Hong Kong Air Pollution Data. Hong Kong.

[17] Javid, \& Munir. (2011). The price puzzle and transmission mechanism of monetary policy in Pakistan: Structural vector autoregressive approach. MPRA Paper No. 30670.

[18] Jayne, Thomas, \& Robert. (2006). The Effects of Government Maize Marketing Policies On Maize Market Prices. In Kenya. In Contributed Paper Prepared for Presentation at the International Association of Agricultural Economists' Conference. Gold Coast, Australia.

[19] Kilavi, M. (2012). Kenya's Climate. Kenya.

[20] Kimani. (2015). Climate Change on Agricultural: Challenges on Maize Production in Uasin Gishu and Trans Nzoia Counties. Department of Meteorology. University of Nairobi.

[21] Lutkepohl. (2005a). New Introduction to Multiple Time Series Analysis. Springer, Berlin.

[22] Lutz, K. (2009). Not All Oil Price Shocks Are Alike: Disentangling Demand and Supply Shocks in the Crude Oil Market. The American Economic Review No. 99.

[23] Maccini, \& Yang. (2009). Under The Weather: Health, Schooling, and Economic Consequences of Early-Life Rainfall. American Economic Review.99 (3).

[24] McPhail, Lu, L., Du, X., \& Muhammad. A. (2012). Disentangling Corn Price Volatility: The Role of Global Demand, Speculation, and Energy. Journal of Agricultural and Applied Economics.

[25] Melolinna, \& Marko. (2012). Macroeconomic Shocks in an Oil Market VAR. European Central Bank.

[26] Mirza, M. (2003). Climate Change and Extreme Weather Events: Can Developing Countries Adapt? Climate Policy.

[27] Murungaru. (2003). Opening Statement by the Minister of
State, Office of the President Republic of Kenya during the Second Conference on Early Warning Systems. OpeningStatement.

[28] Ongamo, Raij, L., Dupas, Moyal, Calatayud, \& Silvain. (2006). Distribution, Pest Status and Agro-Climatic Preferences of Lepidopteran Stem Borers of Maize in Kenya. In Annales de la Socie Entomologique de France.

[29] Oseni, \& Masarirambi. (2011). Effect of Climate Change on Maize (Zea Mays) Production and Food Security in Swaziland. Change, 2, 3 .

[30] Oyinbo, Adegboye, \& Sulaiman. (2010). Retrospective Study of Causal Relationship between Climate Variability and Crop Production in Nigeria. Journal of Occupational Safety and Environmental Health.

[31] Rocha, \& Soares. (2015). Water Scarcity and Birth Outcomes in the Brazilian Semiarid. Journal of Development Economics.

[32] Rojas, Vrieling, \& Rembold. (2011). Assessing Drought Probability for Agricultural Areas in Africa with Coarse Resolution Remote Sensing Imagery. Remote Sensing of Environment,

[33] Schwarz. (1978). Estimating the dimension of a model. Annals of Statistics.

[34] Shibata. (1980). Asymptotically Efficient Selection of the Order of the Model for Estimating Parameters of a Linear Process. Annals of Statistics,

[35] Sims. (1980). Macroeconomics and Reality. Econometrica.

[36] Sims, \& Zha. (2006). Were There Regime Switches in Us Monetary Policy. American Economic Review 96, 5481.

[37] Tewari, Mehlhorn, Parrott, \& Hill. (2015). Climatic Variability and Crop Price Trends in West Tennessee: A Bivariate Granger Causality Analysis. European Scientific Journal.

[38] Tsay, R. S. (2013). Multivariate Time Series Analysis: With R and Financial Applications. John Wiley \& Sons.

[39] Zhang, Vedenov, \& Wetzstein. (2007). Can the US Ethanol Industry Compete in the Alternative Fuels Market? Agricultural Economics. Fuels market? Agricultural Economics. 